\title{
Heterogeneity of Trading Information and the Price-Volume Relationship: Theory and Evidence
}

\author{
Hsinan $\mathrm{Hsu}^{1}$, Tsung-Che $\mathrm{Wu}^{2}$, Grace Shu-hsing $\mathrm{Wu}^{3} \&$ Ya-Hui Chang ${ }^{4}$ \\ ${ }^{1}$ Department of Finance, Feng Chia University, Taiwan \\ ${ }^{2}$ Department of Finance, Chang Jung Christian University, Taiwan \\ ${ }^{3}$ Department of Accounting and Information System, Chang Jung Christian University, Taiwan \\ ${ }^{4}$ Graduate School of Business and Management, Tainan University of Technology, Taiwan \\ Correspondence: Grace Shu-hsing Wu, Department of Accounting and Information System, Chang Jung Christian \\ University, Taiwan. No.1, Changda Rd., Gueiren District, Tainan City 71101, Taiwan (R.O.C.).
}

Received: January 18, 2016

Accepted: February 3, 2016

Online Published: February 4, 2016

doi:10.5430/afr.v5n1p232

URL: http://dx.doi.org/10.5430/afr.v5n1p232

\begin{abstract}
The purpose of this paper is to propose a new theory regarding the heterogeneity of trading information and price-volume relationship. Basically, the heterogeneity of trading information influences the market demand and supply curves of a stock (or equity index), which in turn affects the price-volume relationship for that stock (or index). This theoretical framework helps resolve existing issues regarding price-volume relationships for equities. For example, empirical experience demonstrates that stock price reversals from tops or rebounds from bottoms are often accompanied with extremely large trading volume; however, an abnormal large volume is not always, but more likely, to lead a price reversal (or rebound). This is due to the greatest extent of heterogeneity of trading information among traders at the time of price reversals (or rebounds). Empirically, this investigation focuses on the price-volume relationship surrounding stock price reversals (or rebounds), which clarify the role of information. The results strongly support the proposed framework.
\end{abstract}

Keywords: Price-volume relationship, Price rebounds or reversals, Heterogeneity of trading information, Market demand and supply curves

\section{Introduction}

The price-volume relationship in equity markets has received extensive research attention for at least five decades. There are five hypotheses regarding price-volume relationship of equity in the literature. All these hypotheses suggest varying price-volume relationships, yet they also reach a consensus on two empirical relations that emerge as stylized facts: (1) The correlation between volume $(V)$ and the absolute value of a price change $(|\Delta P|)$ is positive in both equity and futures markets (e.g., Epps and Epps, 1976; Chen et al., 2001), and (2) the correlation between volume and price change per se $(\Delta P)$ is positive in equity markets (e.g., Epps, 1975; Smirlock and Starks, 1985). But when is $V$ positively correlated with $\Delta P$, and when are they negatively correlated? Existing models cannot explain why the trading volume abruptly increases multiple (and even hundreds of) times during stock price rebounds or reversals. Although the SAI model implies a positive correlation between trading volume and the absolute value of price changes, modern technology advances (e.g., networking, communication) make sequential arrival of information unlikely; that is, a piece of information probably does not pass first to investor $\mathrm{A}$ and then to investor B, and so on. Today's investors are equipped with advanced technology, including panel personal computers and mobile phones, such that even if the dissemination of information is sequential, its arrival among investors seems simultaneous.

If so, what causes trading? Black (1986) argues that trading arises due to information noise, in that investors adopt different interpretations of information and prioritize their portfolios of information differently. Trading thus exists because of the heterogeneity of information, which implies a potential mechanism by which this heterogeneity affects the price-volume relationship.

Accordingly, this article proposes a new framework regarding the heterogeneity of trading information and the price-volume relationship. Basically, the heterogeneity of trading information influences market demand and supply 
curves for a stock (or equity index), which in turn affect the price-volume relationship for that stock (or index). This theoretical framework can address existing issues regarding the price-volume relationship for equities relatively easy. For example, empirical experience demonstrates that stock price reversals from tops or rebounds from bottoms are often accompanied by extremely large trading volumes; however, abnormally large volumes tend to lead, though not always, to price reversals (or rebounds). It is possible to explain this trend according to the great extent of heterogeneity in trading information among traders. As an empirical investigation of the proposed framework, this study examines the price-volume relationship around stock price reversals (or rebounds), as well as the characteristics of the long-term price-volume relationship in the Taiwan stock index.

The results strongly support the proposed view. Our theoretical framework and empirical finding contributes to the price-volume relationship literature. This theory is helpful to explain why the trading volume is always abruptly increasing several (even hundred) times in the stock price rebounds (or reversals) and subsequently decreasing; and why a variety of price-volume relationships persist.

The rest of this paper is organized as follows: Section 2 summarizes prior research and outlines the theoretical foundation for the mechanism of heterogeneous trading information and its effects on the price-volume relationship. Section 3 presents some testing hypotheses, along with the empirical methodology, followed by the empirical results in Section 4. Finally, Section 5 concludes findings in this paper.

\section{Prior Research and Theoretical Foundation}

\subsection{Prior Research}

There are five hypotheses regarding price-volume relationship of equity in the literature, namely, the mixture of distribution hypothesis (MDH), the sequential arrival of information (SAI) model, the motives model, the noise trader model, and the asymmetric information model. These models estimate various price-volume relations, depending on the rate of information flow to the market, how the information gets disseminated, and the extent to which market prices convey information.

Clark (1973) suggests that changes in trading volume is positively correlated with changes in price variability; thus trading volume indicates the flow rate of information and implies asymmetry in the price-volume relation (Karpoff, 1987). Related findings in many empirical studies support and extend the MDH (Epps and Epps, 1976; Tauchen and Pitts, 1983; Harris, 1986; Karpoff, 1987; Chen and Fong, 2000; Moosa et al., 2003; Chen and Liao, 2005; Bauwens et al., 2006). However, the SAI model (Copeland, 1976) instead suggests information is disseminated sequentially to market traders, such that new information causes both trading volume and price movements. The theory implies a positive correlation between trading volume and the absolute value of price changes, a claim that also has been supported by several studies (Rogalski, 1978; Jennings et al., 1981; McInish and Wood, 1990; Assogbavi et al., 1995; Huang and Masulis, 2003; Ackert and Athanassakos, 2005).

The motives model (Lakonishok and Smidt, 1989) argues for a correlation between current trading volume and past stock prices, because trading volume provides information about past prices. Empirical studies in support of this model include those by Lakonishok and Maberly (1990), Lamoureux and Lastraps (1990); Loughran and Ritter (1995), Odean, (1998), and Grinblatt and Keloharju (1999). Another option, the noise trader model (Delong et al., 1990), suggests that irrational noise traders in the asset market affect stock prices and earn higher expected returns. Several studies extend this model by using trading volume as a proxy for information; however, information does not explain volatility due to noise trading in the market, so there might be some causal relation between trading volume and stock price changes (Campbell et al., 1993; Chen et al., 2001).

Finally, the asymmetric information model (Kyle, 1985) suggests that informed traders have more information about asset values than uninformed traders, so they also are more likely to earn surplus profits from trading. Several empirical studies support the asymmetric information model (Easley and O'Hara, 1987; Admati and Pfleiderer, 1988; Holden and Subrahmanyam, 1992; Kent et al., 1998; Back et al., 2000; Chakravarty, 2001; Hasbrouck, 2003; Feng and Seasholes, 2004).

Five hypotheses above all suggest the price-volume relation. However, there is no consensus among these five theories. In particular, they cannot explain why the trading volume is always abruptly increasing several times even hundred times in the stock price rebounds or reversals.

\subsection{Heterogeneity of Information and Trading Volume: A Simple Example}

What causes trading? Black (1986) argues that trading can take place due to the noise of information, that is, differences in the availability or interpretations of information. Trading is due to heterogeneous information among 
market traders.

To illustrate this theory, we begin with a simple example. At one time on the Taiwan stock market, the underwriting prices for initial public offering (IPO) stocks were much lower than their prevailing GreTai Securities Market (OTC) market prices. Therefore, when IPO stocks begin trading on the Taiwan Stock Exchange (TSE), their prices needed to increase consecutively for a short period of time (i.e., honeymoon period) (Note 1) due to the price limit. (Note 2) Trading volume usually would be one trading unit (equals 1,000 shares) or several trading units at the beginning of the IPO trading. (Note 3) While approaching the end of the honeymoon period, trading volume would increase gradually; after that, trading volume abruptly increased to several thousand (or more) trading units. Major reason for this variation is information among market participants was nearly homogeneous at the beginning of the IPO trading, but it became increasingly heterogeneous over the honeymoon period and finally reached a high level of heterogeneity around the price reversal.

\subsection{Heterogeneity of Information and Trading Volume: A Theoretical Model}

The market price of a stock, similar to that for commodities, is determined by market demand and supply. However, unlike other commodities, a stock's perceived quality might change according to the information available to the market. For different investors at time $t$, the availability and interpretation of information varies. Thus when the perceived quality of a stock changes, its aggregate demand or supply curves will also change (Note 4), which alters both the price and the trading volume. Significant literature suggests negative slope for demand curves (e.g., Harris and Gurel, 1986; Shleifer, 1986; Blouin et al., 2000; Kim et al., 2009; Petajisto, 2009) and positive slope for supply curves (Bagwell, 1991; Bradley et al., 1988; Brown and Ryngaert, 1992; Bui and Jordan, 2009; Kim et al., 2009). In this paper, we will follow these views of negatively sloped demand curves and positively sloped supply curves.

\subsubsection{Dynamic Bull Markets}

We begin by illustrating the dynamic between information heterogeneity and the price-volume relationship in bull markets. Suppose that a stock is initially in a state of equilibrium at time $t=0$, with price $P_{u}^{0}$ and volume $V_{u}^{0}$, at the intersection of the market demand curve $D_{u}^{0}$ and supply curve $S_{u}^{0}$ (Fig. 1). At this moment, some information gets released into the market. The information is good news, but investors' interpretations varies. Some investors (optimists) evaluate it much better than the average, whereas others (pessimists) interpret it as good but less positive than the average. Because the perceived quality of the stock has changed, the market demand curve moves rightward to $D_{u}^{1}$, and the market supply curve moves leftward to $S_{u}^{1}$. (Note 5) If the number of optimists is much greater than the number of pessimists, the movement of the market demand curve is much greater than that of the supply curve, which yields an increase of stock price and trading volume. (Note 6) If the information gets released consecutively to the market, the dynamic interaction between information heterogeneity and the price-volume relationship continues - which interprets the increase of stock price and trading volume in bull markets.

The IPO trading scenario introduced in Section 2.2, when company suddenly releases news with tremendous market profit potential with a price limit, constitutes a special case of the model above. The market supply curve $\left(S_{u}^{0}\right)$ is initially vertical (Fig. 2), and the market demand curve moves continuously upward $\left(D_{u}^{0}, D_{u}^{1}, \ldots\right)$ to intersect with the market supply curve. The return on the stock each trading day thus equals the price limit, until the stock price fully reflects the information available. Thus our model can be applied. 


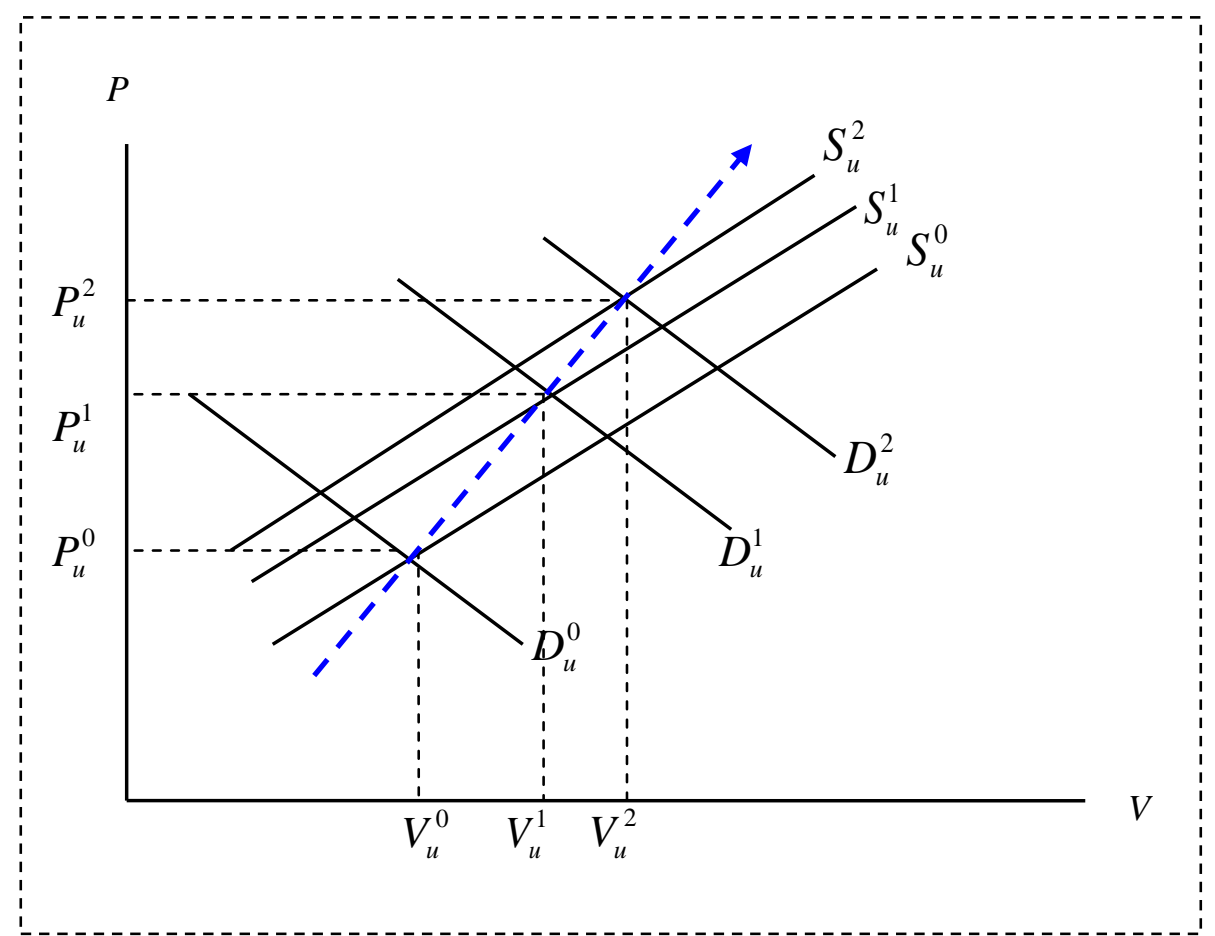

Figure 1. Impact of heterogeneous information on market demand and supply:

Initial-stage stock price increases

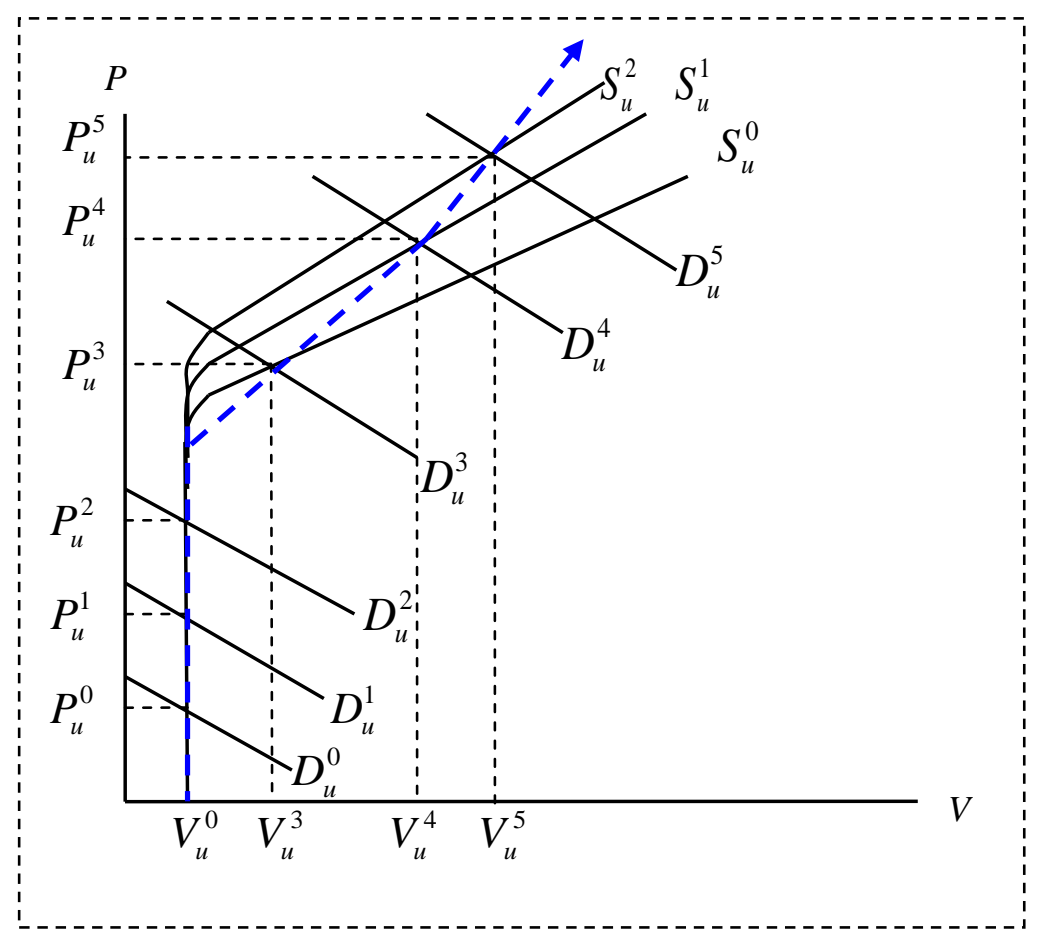

Figure 2. Demand and supply for an IPO stock in a market with a price limit

\subsubsection{Dynamic Price Reversals from the Highest Level}

Regardless of the positive nature of information released and the highest level of stock price, as stock prices increase, some informed investors become aware that the market has overreacted and that the market price has exceeded the stock's intrinsic value. Thus, the number of optimist declines and the number of pessimist rises. In this situation, the 
market demand curve ( $D_{r}^{0}$ ) might intersect the market supply curve $\left(S_{r}^{0}\right)$ at the point at which market price is $P_{r}^{0}$ and trading volume is $V_{r}^{0}$ (Fig. 3). If the number of pessimists greatly surpasses the number of optimists, the market supply curve will move rightward to $S_{r}^{1}$, but the market demand curve can move upward to $D_{r}^{1}$ or downward to $D_{r}^{2}$. Thus the trading volume abruptly increases to $V_{r}^{1}$ or $V_{r}^{2}$, but the price eventually reverses from the highest level to $P_{r}^{1}$ or $P_{r}^{2}$, depending on how heterogeneous the information is.

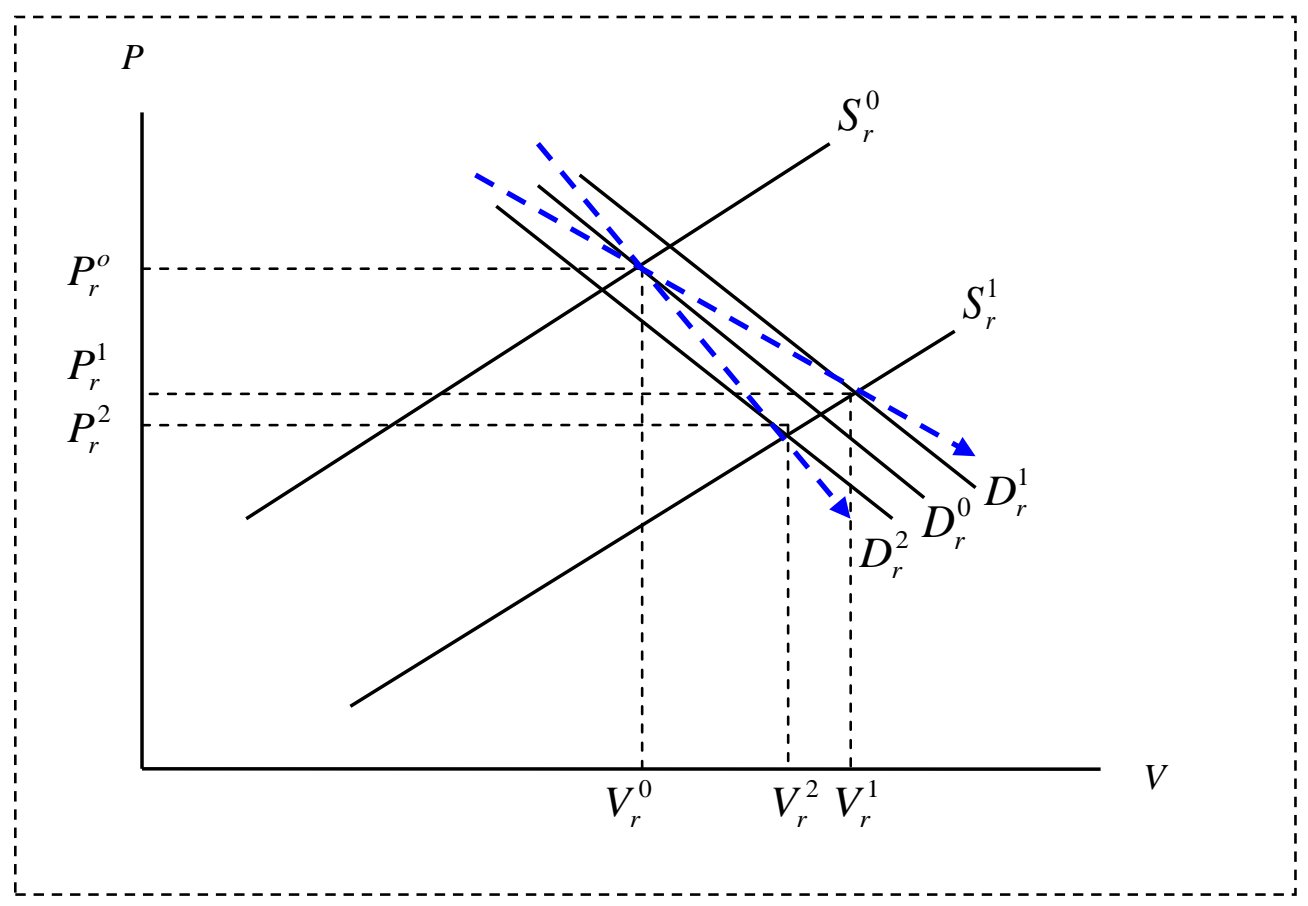

Figure 3. Impact of heterogeneous information on market demand and supply at the stock price reversal from a top

\subsubsection{Dynamic Bear Markets}

In this section, we illustrate the dynamic between information heterogeneity and price-volume relationships in bear markets. Suppose a stock is initially in a state of equilibrium at time $t=0$, with price $P_{d}^{0}$ and volume $V_{d}^{0}$, at the intersection of the market demand curve $D_{d}^{0}$ and supply curve $S_{d}^{0}$ (Fig. 4). At this moment, information gets released into the market; this bad news prompts varying interpretations among investors. The optimists recognize it as bad, but not as bad as average, whereas the pessimists interpret it as worse than average. The perceived quality of the stock changes, the market demand curve moves leftward to $D_{d}^{1}$, and the market supply curve moves rightward to $S_{d}^{1}$. If the number of pessimists is much greater than the number of optimists, the movement of the market demand curve is much greater than that of the supply curve. Thus, the stock price falls, and trading volume decreases. (Note 7) If the bad news gets released continuously to the market, this dynamic interaction between information heterogeneity and the price-volume relationship persists, which interprets the decrease of stock prices and trading volume in bear markets. 


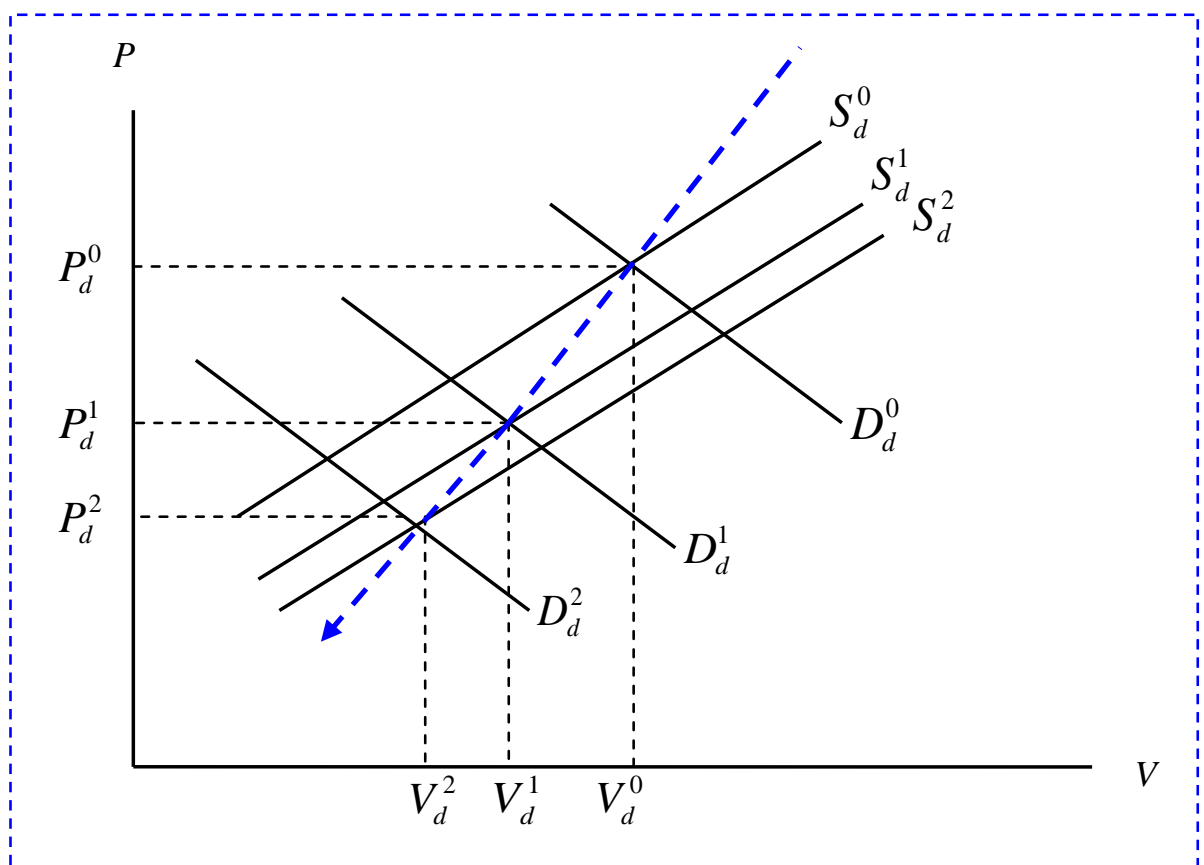

Figure 4. Impact of heterogeneous information on market demand and supply at the stage of stock price falling down 2.3.4 Dynamic Price Rebounds

Regardless of the bad information or the depths to which the stock price sinks though, as the stock price falls, some informed investors recognize that the market has overreacted and that the intrinsic value of stock exceeds its market price. The number of optimists then increases, and pessimists increase fewer. In this situation, the market demand curve $\left(D_{r}^{0}\right)$ might intersect the market supply curve $\left(S_{r}^{0}\right)$ at the point where market price is $P_{r}^{0}$ and trading volume is $V_{r}^{0}$ (Fig. 5). If the number of optimists greatly surpasses the number of pessimists, the market demand curve will move upward to $D_{r}^{1}$, but the market supply curve might move rightward to $S_{r}^{1}$ or leftward to $S_{r}^{2}$. Thus trading volume abruptly increases to $V_{r}^{1}$ or $V_{r}^{2}$, and price eventually rebounds from the bottom to $P_{r}^{1}$ or $P_{r}^{2}$, depending on how heterogeneous the information is.

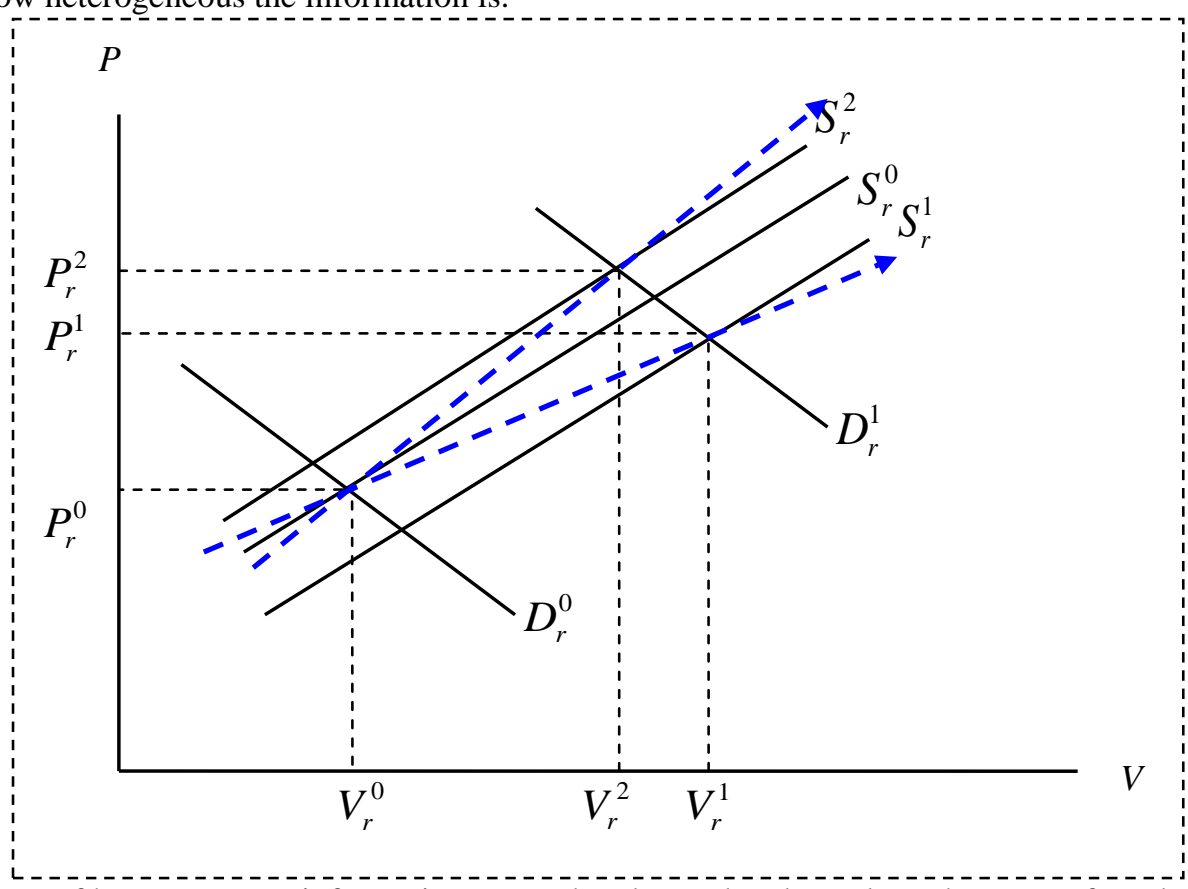

Figure 5. Impact of heterogeneous information on market demand and supply at the stage of stock price rebound from a bottom 


\section{Testing Hypotheses and Methodology}

\subsection{Testing Hypotheses}

Practical experience shows that trading volume increases as stock price rises, such that some investors with accurate information acknowledge the ascending trend. When optimistic investors outnumber pessimistic investors, the stock price continues to rise. This dynamic interaction persists in the process of stock price increases, such that the trading information becomes more and more heterogeneous among investors. The stock price cannot go up infinitely though, so when it reaches a certain level, investors with sufficient information realize that the stock is overpriced and start selling their shares (including short-selling). As soon as the amount of shares sold exceeds the amount purchased by optimistic investors, the stock price reverses, resulting in a boost in trading volume. Similarly, when the stock price falls, the trading volume tends to decline, because investors' opinions become more homogeneous toward downward stock trends. If pessimistic investors outnumber optimistic investors, the stock price will continue to fall, but in this case, the stock price also cannot decline infinitely. When it drops to a certain level, investors with sufficient information realize that the stock is underpriced and start purchasing it. As soon as the amount of shares purchased exceeds the amount sold by pessimistic investors, the stock price rebounds, resulting in a boost in trading volume. Therefore, investor opinions are heterogeneous toward downward stock price trends too. We propose in turn

$H_{1}$ : Trading volume on the day of a stock price rebound or reversal is greater than the trading volumes on the previous and following trading days.

The inverse of $H_{1}$ also is probably true, especially for abnormal volume increases, because relatively large trading volumes imply greater disagreement among traders and should be accompanied by price reversals or rebounds. Thus, we anticipate:

$\mathrm{H}_{2}$ : Greater trading volume increases the likelihood of price reversals or rebounds.

Finally, as stock prices rise or fall, trading information likely grows increasingly heterogeneous, which drives gradual volume increases. We predict:

$H_{3}$ : The absolute value of the stock price change correlates positively with trading volume.

Whether our conjecture in $\mathrm{H}_{3}$ holds or not does not imply that the theory in Section 2 is correct or incorrect though, since the heterogeneousness of information can change.

\subsection{Empirical Methodology}

\subsubsection{Data}

For this study, we collect the following data from the Taiwan Economic Journal database: the daily closing price and trading volume of each stock listed on the TSE, as well as the daily closing price, total number of trading units, and trading value of the TSE Taiwan Capitalization Weighted Stock Index (TAIEX). The sample period is from January 1995 to December 2008.

Since there is no clear definition for reversals (rebounds), for our data collection we define a stock price reversal (rebound) as a stock price that drops (rises) accumulatively by more than $14 \%$ from its most recent high (low) point. Considering the vast number of reversals and rebounds, we limit the sample period for testing $H_{1}$ to January 2005 through December 2008.

\subsubsection{Methodology}

To test $H_{1}$, we define the relative volume ratio $\left(V_{t_{0}} / V_{t_{0} \pm i}, i=1,2,3, \ldots\right)$, where $V_{t_{0}}$ is the volume at the date of reversal (rebound) $\left(t_{0}\right)$, and $V_{t_{0} \pm i}$ is the volume at date $t_{0} \pm i$. We use $t$-tests to determine the significance of the relative volume ratio at date $t_{0} \pm i$.

For our test of $\mathrm{H}_{2}$, we define the multiple of volume increasing ( $\left.m=V_{t} / V_{t-1}\right)$ and the percentage of the price change $\left(\Delta p=\left(P_{t}-P_{t-1}\right) / P_{t-1}\right)$. For each category $\left(m_{i}, \Delta p_{j}\right), i=1,2, \ldots, m$, and $j=1,2, \ldots, n$, we calculate the total number of observations, the number of reversals or rebounds, and the ratio of the number of reversals or rebounds to the total number of observations.

Finally, to verify $\mathrm{H}_{3}$, we employ two regression models that refer to the price-value relationship:

$$
\text { Model 1: }\left|\Delta P_{t}\right|=\alpha+\beta V_{t}+e_{t},
$$


where

$\left|\Delta P_{t}\right|=$ absolute price change in price between date $t$ and date $t-1$.

$V_{t}=$ total trading value for the TAIEX on date $t$.

$e_{t}=$ error term on date $t$.

In our second regression model, we detect the asymmetric impact of price increases or decreases on the price-volume relationship:

$$
\text { Model 2: }\left|\Delta P_{t}\right|=\alpha_{1}+\left(\alpha_{2}-\alpha_{1}\right) D_{1 t}+\beta_{1} V_{t}+\left(\beta_{2}-\beta_{1}\right) D_{2 t}+e_{t} \text {, }
$$

where

$$
\begin{gathered}
D_{1 t}=\left\{\begin{array}{l}
1, \text { when } \Delta P_{t}>0 \\
0, \text { when } \Delta P_{t}<0
\end{array} .\right. \\
D_{2 t}=\left\{\begin{array}{ll}
D_{1} \times V_{t}, & \text { when } \Delta P_{t}>0 \\
0, & \text { when } \Delta P_{t}<0
\end{array} .\right.
\end{gathered}
$$

If the coefficient of $D_{2 t}$ is significant, there is an asymmetric impact on the price-volume relationship during price increases or decreases.

\section{Empirical Results}

\subsection{Testing $H_{1}$}

To test $H_{1}$, we analyze and compare the changes of trading volume between the day of stock price rebound (and reversal) and the days before and after. In Table 1.1 (and Table 1.2) we present the descriptive statistics of trading volume in a period from three days before to three days after the price rebound (and reversal); Table 2.1 (and Table 2.2) exhibits $t$-test for the significance of volume changes in the case of price rebound (and reversal) during the period above.

As shown in Table 1.1, for the rebound sample, the relative volume ratios $\left(V_{t_{0}} / V_{t_{0} \pm i}\right)$ decrease from $t_{-3}$ to $t_{0}$, indicating a gradual increase in trading volume. The trading volume on the day of the rebound is over three times greater than the trading volume during the three days prior to the rebound $\left(t_{-1} \rightarrow t_{-3} ; 3.87-3.07\right.$ times greater). The average trading volume for the three days after the rebound $\left(t_{+3}\right)$ also are smaller than that for the day of rebound, yet increasing after the rebound. The $t$-test results in Table 2.1, used to determine whether the differences in the relative volume ratios from three days before to three days after the rebound $\left(t_{-3} \rightarrow t_{+3}\right)$ are significant, confirm that the relative volume ratio is significantly different between one day before and two days before, as well as three days before ( 0.01 level). The difference between relative volume ratios two days before and that in three days before is not significant $(0.1$ level) though. That is, the trading volume on the day of rebound is significantly different from those one, two, or three days before the rebound. The relative volume ratio one day after the rebound is significantly different from that in two days after $(0.1$ level $)$ and three days after $(0.01$ level). The relative volume ratio two days after the rebound is also significantly different from that in three days after $(0.05$ level). Thus, the relative volume ratios correlate positively between one day after and two and three days after the rebound, as well as between two days after and three days after the rebound.

Table 1.2 exhibits changes in the trading volume for a reversal. The trading volume increases from three days before to two days before, then diminishes on the day before the reversal. Average trading volume increases drastically on the day of the reversal (4.4 and 2.65 times compared with $t_{-3}$ and $t_{-2}$, respectively) and then shrinks abruptly after the reversal (approximately $1 / 2.4\left[t_{+1}\right]$ to $1 / 10.5\left[t_{+3}\right]$ times the volume on $t_{0}$ ). The results in Table 2.2 reveal no significant differences between the changes of trading volume during three days before the reversal but significant differences existed in the relative volume ratios one day after versus two and three days after the reversal, as well as between two days after and three days after $(0.1$ level). Therefore, trading volume varies significantly each day. This empirical evidence offers support for $H_{1}$. 
Table 1.1 Descriptive statistics: Relative volume ratios $\left(V_{t_{0}} / V_{t_{0} \pm i}\right)$ before and after stock rebounds

\begin{tabular}{crrrr}
\hline Samples & Average & Standard Deviation & Maximum & Minimum \\
\hline$t_{-3}$ & 3.8663 & 7.4876 & 76.6190 & 0.1321 \\
$t_{-2}$ & 3.6414 & 6.1700 & 87.5366 & 0.1196 \\
$t_{-1}$ & 3.0737 & 3.3476 & 31.4754 & 0.0788 \\
$t_{+1}$ & 1.3056 & 1.7829 & 27.7414 & 0.0539 \\
$t_{+2}$ & 1.1992 & 1.6265 & 22.6620 & 0.0403 \\
$t_{+3}$ & 1.0759 & 1.5859 & 19.8642 & 0.0227
\end{tabular}

$V_{t}$ represents trading volume at the date of rebound $(t)$

Table 1.2 Descriptive statistics: Relative volume ratios $\left(V_{t_{0}} / V_{t_{0} \pm i}\right)$ before and after stock reversals

\begin{tabular}{crrrr}
\hline Samples & Average & Standard Deviation & Maximum & Minimum \\
\hline$t_{-3}$ & 4.4058 & 18.2367 & 176.2400 & 0.1710 \\
$t_{-2}$ & 2.6535 & 3.6576 & 30.5966 & 0.4256 \\
$t_{-1}$ & 3.0687 & 9.6455 & 93.1176 & 0.2872 \\
$t_{+1}$ & 2.4021 & 4.6098 & 43.0000 & 0.3390 \\
$t_{+2}$ & 6.2616 & 29.0516 & 256.3095 & 0.2080 \\
$t_{+3}$ & 10.5176 & 57.8722 & 512.6190 & 0.2614 \\
\hline
\end{tabular}

$V_{t}$ represents trading volume at the date of reversal $(t)$

Table $2.1 t$-test results for the difference of trading volumes, three days before to three days after a stock rebound

\begin{tabular}{clllll}
\hline & \multicolumn{2}{c}{ Panel A. Before Rebound } & & \multicolumn{2}{c}{ Panel B. After Rebound } \\
\hline & 2 days before & 3 days before & & 2 days after & 3 days after \\
\hline 1 day before & $-2.3862^{* * *}$ & $-2.3027^{* * *}$ & 1 day after & $1.5425^{*}$ & $2.9095^{* * *}$ \\
2 days before & & -0.6730 & 2 days after & & $1.8915^{* *}$ \\
\hline
\end{tabular}

*** Significant at 0.01 . ** Significant at 0.05 . $*$ Significant at 0.1 .

Table $2.2 \mathrm{t}$-test results for the difference of trading volumes, three days before to three days after a stock reversal

\begin{tabular}{clllll}
\hline & \multicolumn{2}{c}{ Panel A. Before Reversal } & \multicolumn{2}{c}{ Panel B. After Reversal } \\
\hline & 2 days before & 3 days before & & 2 days after & 3 days after \\
\hline 1 day before & -0.6390 & -0.6390 & 1 day after & $-1.2933^{*}$ & $-1.3660^{*}$ \\
2 days before & & -0.9603 & 2 days after & & $-1.4269^{*}$ \\
\hline
\end{tabular}

$* * *$ Significant at 0.01 .** Significant at 0.05 . * Significant at 0.1 .

4.2 Testing $\mathrm{H}_{2}$

The results of the frequencies of price reversals (rebounds) in Table 3.1, 3.2, and 3.3 indicate number of observations belong to the reversals (rebounds) for a specific multiple of volume increasing $\left(m_{i}\right)$ and a percentage of a price change ( $\Delta p_{j}$ ). For example, in Table 3.1, of the 1,531 observations, 229 (14.96\%) can be classified as reversals or rebounds for volume changes $(m)$ of 3-5 times and price changes ( $\Delta p)$ of $-7 \%$ to $-4 \%$. Although the percentages of reversals or rebounds in each category of abnormal volume increases are not particularly high, the greater the price change, the more likely the observation is to be a reversal or rebound. This tendency becomes particularly obvious when the multiple of volume increases. For example, if an investor observes that the volume of a stock increases by 3 to 5 times (as in Table 3.1) and its price declines between $-4 \%$ and $-7 \%$, then approximately $15 \%$ of 
the related observations feature a reversal. If the volume increases more than 10 times (as in Table 3.3) and its price declines between $-4 \%$ and $-7 \%$, approximately $29 \%$ of observations will be a reversal. Thus, we find support for $H_{2}$.

Table 3.1 Frequencies of reversals or rebounds with multiple of volume increasing $\left(3 \leqq m_{i}<5\right)$ and percentage of the price change $\left(\Delta p_{j}\right)$

\begin{tabular}{|c|c|c|c|c|c|c|}
\hline & \multicolumn{6}{|c|}{ Percentages of Price Changes $\left(\Delta p_{j}\right)$} \\
\hline & $-7 \%$ & $-4 \%$ & $-1 \%$ & $+1 \%$ & $+4 \%$ & \\
\hline & $\begin{array}{c}\leqq \\
-4 \%\end{array}$ & $\begin{array}{c}\leqq \Delta p< \\
-1 \%\end{array}$ & $\leqq \Delta p<$ & $\leqq \underset{4 \%}{\Delta p}<$ & $\leqq \underset{7 \%}{\Delta p}<$ & Total \\
\hline Observations & 1,531 & 3,022 & 6,259 & 9,829 & 7,540 & 28,181 \\
\hline Number of reversals or rebounds & 229 & 91 & 56 & 321 & 1058 & 1,755 \\
\hline Percentage & $14.96 \%$ & $3.01 \%$ & $0.89 \%$ & $3.27 \%$ & $14.03 \%$ & $6.23 \%$ \\
\hline
\end{tabular}

$m$ denotes the multiple of volume increasing $\left(m=V_{t} / V_{t-1}\right) . V_{t}$ is the volume at the date of reversal (rebound) ( $t$ ) and $\Delta p$ is the percentage of the price change $\left(\Delta p=\left(P_{t}-P_{t-1}\right) / P_{t-1}\right)$.

Table 3.2 Frequencies of reversals or rebounds with multiple of volume increasing $\left(5 \leqq m_{i}<10\right)$ and percentage of the price change $\left(\Delta p_{j}\right)$

\begin{tabular}{|c|c|c|c|c|c|c|}
\hline & \multicolumn{6}{|c|}{ Percentages of Price Changes $\left(\Delta p_{j}\right)$} \\
\hline & $-7 \%$ & $-4 \%$ & $-1 \%$ & $+1 \%$ & $+4 \%$ & \\
\hline & $\begin{array}{c}\leqq \\
-4 \%\end{array}$ & $\begin{array}{c}\leqq \\
-1 \% \\
-1 \%\end{array}$ & $\begin{array}{c}\Delta p< \\
1 \%\end{array}$ & $\leqq \underset{4 \%}{\Delta \%}<$ & $\leqq \begin{array}{c}\Delta p< \\
7 \%\end{array}$ & Total \\
\hline Observations & 563 & 872 & 1,927 & 2,961 & 3,859 & 10,182 \\
\hline Number of reversals or rebounds & 91 & 31 & 25 & 101 & 525 & 773 \\
\hline Percentage & $16.16 \%$ & $3.56 \%$ & $1.30 \%$ & $3.41 \%$ & $13.60 \%$ & $7.59 \%$ \\
\hline
\end{tabular}

$m$ denotes the multiple of volume increasing $\left(m=V_{t} / V_{t-1}\right) . V_{t}$ is the volume at the date of reversal (rebound) $(t)$ and $\Delta p$ is the percentage of the price change $\left(\Delta p=\left(P_{t}-P_{t-1}\right) / P_{t-1}\right)$.

Table 3.3 Frequencies of reversals or rebounds with multiple of volume increasing $\left(m_{i}>10\right)$ and percentage of the price change $\left(\Delta p_{j}\right)$

\begin{tabular}{|c|c|c|c|c|c|c|}
\hline & \multicolumn{6}{|c|}{ Percentages of Price Changes $\left(\Delta p_{j}\right)$} \\
\hline & $-7 \%$ & $-4 \%$ & $-1 \%$ & $+1 \%$ & $+4 \%$ & \\
\hline & $\begin{array}{c}\leqq \\
-4 \%\end{array}$ & $\begin{array}{c}\leqq \\
-1 \%\end{array}$ & $\leqq \underset{1 \%}{\Delta p}<$ & $\leqq \underset{4 \%}{\Delta p}<$ & $\leqq \underset{7 \%}{\Delta p}<$ & Total \\
\hline Observations & 249 & 354 & 706 & 746 & 1067 & 3,122 \\
\hline Number of reversals or rebounds & 72 & 18 & 14 & 25 & 183 & 312 \\
\hline Percentage & $28.92 \%$ & $5.08 \%$ & $1.98 \%$ & $3.35 \%$ & $17.15 \%$ & $10.00 \%$ \\
\hline
\end{tabular}

$m$ denotes the multiple of volume increasing $\left(m=V_{t} / V_{t-1}\right) . V_{t}$ is the volume at the date of reversal (rebound) ( $t$ )

and $\Delta p$ is the percentage of the price change $\left(\Delta p=\left(P_{t}-P_{t-1}\right) / P_{t-1}\right)$.

\subsection{Testing $\mathrm{H}_{3}$}

To investigate the correlation between the absolute value of stock price change and trading volume, we adopt two models for verification. Model 1 illustrates a positive correlation between the absolute value of a stock price change and trading volume; Model 2 provides an additional investigation to detect asymmetric effects on the price-volume relationship during stock price increases or decreases.

The regression results for Model 1 is shown in Table 4; Panel A and B reveal the correlations between the absolute value of price change and trading volume in terms of the number of trading units (1,000 shares) and trading value (in NT dollars), respectively. Regression results for the whole period (January 1995 to December 2008) in Panel A indicate that the coefficient $(\beta=2.1 \mathrm{E}-06)$ of trading volume in terms of trading units is significant at the 0.01 level; that is, trading volume increases during both stock price increases and decreases. When the trading volume increases (decreases) by 1 million shares, the stock price index goes up (down) by 2 points. In general, the absolute value of a 
stock price change exhibits a positive correlation with trading volume. We also divide our sample period into three subperiods, (Note 8) as in Panel A of Table 4. The coefficients $(\beta)$ of trading volume for period 1,2 and 3 are 2.04E-05, 3.64E-06, and 5.67E-06, respectively, with significance levels of $0.001,0.1$, and 0.001 , respectively. Thus we confirm a positive correlation between the absolute value of stock price change and trading volume, which suggests that investors' opinions become more heterogeneous as trading volume increases (decreases).

Similarly, Panel B of Table 4 shows that the regression coefficient ( $\beta=3.5 \mathrm{E}-07)$ of trading volume in terms of trading value is significant at the 0.001 level; trading volume increases as the stock price rises. Specifically, the stock price index grows by 3.5 points when trading volume increases by NT $\$ 10$ million. For our three subperiods (Period 1 to 3 in Panel B), the coefficients $(\beta)$ of trading volume are 3.59E-07, 3.41E-07, and 2.66E-07, respectively; all are significant at the 0.001 level. Results in Period 1 (January 1995-December 1998) and Period 2 (January 1999-December 2003) confirm that the stock price index grows to 3.59 and 3.41 points, respectively, when the trading volume increases by NT $\$ 10$ million. Results in Period 3 (January 2003-March 2007) indicate an increase of 2.66 points in the stock price index with the same trading volume increase. The absolute value of the stock price change thus is positively correlated with trading volume in terms of trading value. This empirical result, as the result in Panel A, is consistent with the empirical finding of Jennings et al. (1981), McInish and Wood (1990), and Ackert and Athanassakos (2005). As results in Table 4 reveals, regardless of the presentation of trading volume in terms of the number of trading units or trading value, the results remain consistent.

Table 4. Regression results for the correlation between the absolute value of stock price change and volume $\left(\left|\Delta P_{t}\right|=\alpha+\beta V_{t}+e_{t}\right)$

\begin{tabular}{|c|c|c|c|c|c|c|c|c|}
\hline & \multicolumn{4}{|c|}{ Panel A. Volume in trading units } & \multicolumn{4}{|c|}{ Panel B. Volume of trading values } \\
\hline Coeff. & Whole Period & Period 1 & Period 2 & Period 3 & Whole Period & Period 1 & Period 2 & Period 3 \\
\hline$\alpha$ & $\begin{array}{c}64.51 \\
* * *\end{array}$ & $\begin{array}{c}35.04 \\
* * *\end{array}$ & $\begin{array}{c}79.22 \\
* * *\end{array}$ & $\begin{array}{c}29.01 \\
* * *\end{array}$ & $\begin{array}{c}39.18 \\
* * *\end{array}$ & $\begin{array}{c}41.75 \\
* * *\end{array}$ & $\begin{array}{c}55.92 \\
* * *\end{array}$ & $\begin{array}{c}26.96 \\
* * *\end{array}$ \\
\hline & $(25.65)$ & $(8.38)$ & $(12.79)$ & $(7.08)$ & $(15.83)$ & $(12.17)$ & $(10.54)$ & $(6.47)$ \\
\hline$\beta$ & $\begin{array}{c}2.1 \mathrm{E}-06 \\
* * *\end{array}$ & $\begin{array}{c}2.0 \mathrm{E}-05 \\
* * *\end{array}$ & $\begin{array}{c}3.7 \mathrm{E}-06 \\
*\end{array}$ & $\begin{array}{c}5.7 \mathrm{E}-06 \\
* * *\end{array}$ & $\begin{array}{c}3.5 \mathrm{E}-07 \\
* * *\end{array}$ & $\begin{array}{c}3.6 \mathrm{E}-07 \\
* * *\end{array}$ & $\begin{array}{c}3.4 \mathrm{E}-07 \\
* * *\end{array}$ & $\begin{array}{c}2.7 \mathrm{E}-07 \\
* * *\end{array}$ \\
\hline & $(2.57)$ & $(9.58)$ & $(1.77)$ & $(5.72)$ & (14.19) & $(10.11)$ & (7.07) & $(6.13)$ \\
\hline$R^{2}$ & 0.0021 & 0.0752 & 0.0031 & 0.0303 & 0.059 & 0.0832 & 0.0465 & 0.0347 \\
\hline $\bar{R}^{2}$ & 0.0017 & 0.0744 & 0.0021 & 0.0293 & 0.0587 & 0.0823 & 0.0455 & 0.0337 \\
\hline
\end{tabular}

Notes: The whole period covers January 1995-December 2008. Period 1 covers January 1995-December 1998; Period 2 is January 1999-December 2003; and Period 3 covers January 2004-December 2008. Figures in parentheses are $t$-values.

*** Significant at 0.01 . ** Significant at 0.05 . * Significant at 0.1 .

We also investigate the potential asymmetric effects on the price-volume relationship during stock price increases and decreases, using regression Model 2. The results in Table 5 feature trading volume in terms of both the number of trading units (Panel A, 1,000 shares) and trading value (Panel B, NT dollars).

According to Panel A of Table 5, the $\beta_{1}$ coefficients are not significant for the whole research period, subperiod 1, or subperiod 2, but $\beta_{1}$ coefficient is significant in subperiod 3. All the $\beta_{2}-\beta_{1}$ coefficients are significant for each period. Therefore, we find a positive correlation between price and volume when the stock price increases ( $\beta_{2}$ $=\beta_{1}+\beta_{2}-\beta_{1}$ ) for the whole research period, subperiod 1, and subperiod 2. In contrast, the relationship between price and volume is not significant $\left(\beta_{1}\right)$ during stock price drops for the whole research period, subperiod 1 , and subperiod 2. That is, we find an asymmetric effect on the price-volume relationship during stock price increases and decreases, with the exception of subperiod 3, during which the price-volume relationship still demonstrates an asymmetric effect but is consistently significant during price drops.

Similarly, the results pertaining to trading volume in terms of trading value in Panel B reveal an asymmetric effect. The coefficient $\beta_{1}$ is significant during the whole research period and all three subperiods; all coefficients $\beta_{2}-\beta_{1}$ are significant across our study periods as well. When the stock price increases, there is a positive correlation between price and volume $\left(\beta_{2}=\beta_{1}+\beta_{2}-\beta_{1}\right)$. The relationship between price and volume $\left(\beta_{1}\right)$ remains significant when the stock price falls. Thus we again find an asymmetric effect on the price-volume relationship during both price increases and decreases. Results found in Panel A and B are generally consistent with the finding of Easley and O'Hara (1987), Kent, Hirshleifer, and Subrahmanyam. (1998), and Back, Cao, and Willard 
(2000).

Table 5. Regression results for the asymmetric effect on the price-volume relationship $\left(\left|\Delta P_{t}\right|=\alpha_{1}+\left(\alpha_{2}-\alpha_{1}\right) D_{1 t}+\beta_{1} V_{t}+\left(\beta_{2}-\beta_{1}\right) D_{2 t}+e_{t}\right)$

\begin{tabular}{ccccccccc}
\hline & \multicolumn{3}{c}{ Panel A. Volume of trading units } & \multicolumn{3}{c}{ Panel B. Volume of trading values } \\
\hline Coeff. & Whole & Period 1 & Period 2 & Period 3 & Whole & Period 1 & Period 2 & Period 3 \\
\hline \multirow{2}{*}{$\alpha_{1}$} & 57.83 & 57.77 & 79.41 & 32.59 & 52.14 & 55.63 & 71.69 & 33.28 \\
& $* * *$ & $* * *$ & $* * *$ & $* * *$ & $* * *$ & $* * *$ & $* * *$ & $* * *$ \\
& $(24.98)$ & $(15.11)$ & $(15.66)$ & $(11.43)$ & $(22.65)$ & $(15.31)$ & $(14.21)$ & $(11.44)$ \\
$\alpha_{2}-\alpha_{1}$ & 10.24 & -0.33 & 3.82 & 14.65 & 4.51 & 1.75 & -4.01 & 13.48 \\
& $(3.11)$ & $(-0.06)$ & $(0.52)$ & $(3.60)$ & $(1.35)$ & $(0.33)$ & $(-0.54)$ & $(3.28)$ \\
& $-6 \mathrm{E} 07$ & $-3.2 \mathrm{E}-06$ & $3.3 \mathrm{E}-06$ & $-9.4 \mathrm{E}-06$ & $-4 . \mathrm{E}-07$ & $-3.3 \mathrm{E} 07$ & $-3.4 \mathrm{E}-07$ & $-3.6 \mathrm{E}-07$ \\
$\beta_{1}$ & & & & $* * *$ & $* * *$ & $*$ & $* * *$ & $* * *$ \\
& $(-0.17)$ & $(-0.37)$ & $(0.42)$ & $(-2.66)$ & $(-4.11)$ & $(-1.97)$ & $(-1.65)$ & $(-2.50)$ \\
& $3.1 \mathrm{E}-05$ & $8.6 \mathrm{E}-05$ & $3.3 \mathrm{E}-05$ & $3.7 \mathrm{E}-05$ & $2.0 \mathrm{E}-06$ & $2.0 \mathrm{E}-06$ & $2.1 \mathrm{E}-06$ & $1.4 \mathrm{E}-06$ \\
$\beta_{2}-\beta_{1}$ & $* * *$ & $* * *$ & $* * *$ & $* * *$ & $* * *$ & $* * *$ & $* * *$ & $* * *$ \\
& $(6.25)$ & $(6.51)$ & $(2.87)$ & $(7.63)$ & $(13.19)$ & $(7.79)$ & $(6.95)$ & $(7.40)$ \\
$R^{2}$ & 0.05 & 0.09 & 0.04 & 0.13 & 0.09 & 0.09 & 0.08 & 0.13 \\
$\bar{R}^{2}$ & 0.05 & 0.09 & 0.04 & 0.13 & 0.09 & 0.09 & 0.08 & 0.13 \\
\hline
\end{tabular}

Notes: The whole period covers January 1995-December 2008. Period 1 covers January 1995-December 1998; Period 2 is January 1999-December 2003; and Period 3 covers January 2004-December 2008. Figures in parentheses are $t$-values.

*** Significant at 0.01 . ** Significant at 0.05 . * Significant at 0.1 .

The major difference between Panel A and B of Table 5 is that during stock price drops, the price-volume relationship measured as the number of trading units is significant, whereas the relationship measured by trading value is insignificant. Perhaps during price drops, the effect on the price-volume relationship for stocks with higher prices is more significant than the effect for stocks with lower prices. This varying effect could cause the price-volume relationship to appear significant with regard to trading units but insignificant with regard to trading value.

\section{Conclusions}

Although the literature on the price-volume relationship is numerous, two empirical relations emerge as stylized facts: (1) The correlation between volume $(V)$ and the absolute value of price change $(|\Delta P|)$ is positive in both equity and futures markets, and (2) the correlation between volume and price change per se $(\Delta P)$ is positive in equity markets. But when should $V$ be positively correlated with $\Delta P$ and when should $V$ be negatively correlated with $\Delta P$ ? In particular, existed findings can hardly explain why the trading volume is always abruptly increasing several (even hundred) times in the stock price rebounds or reversals.

Black (1986) argues that trading is due to noise of information, that is, the interpretation of a piece of information and the priority of a portfolio of information owned by investors can be different. In short, trading is due to the heterogeneity of information among market traders. Thus, the mechanism of the heterogeneity of trading information to the price-volume relationship is the key to answer the role of information in the price-volume relationship.

In this paper, we propose a new hypothesis regarding the heterogeneity of trading information and price-volume relationship. We argue that basically, the heterogeneity of trading information influences the market demand and supply curves of a stock (or an equity index), and hence further influencing the price-volume relationship for the stock (or index). In our view, unlike other commodities, the market demand and supply curves of a stock are dynamically adjusting. Under this theoretical framework, any pattern of the price-volume relationship is possible. Thus, previous issues on the price-volume relationship for equities can easily be resolved. For example, empirical finding demonstrates that stock price reversals from tops or rebounds from bottoms are often accompanied with extremely large trading volume; however, abnormal large volume is not always, but more likely, to lead price reversals (or rebounds). This is due to the greatest extent of heterogeneity of trading information among traders in the price reversals or rebounds.

Empirically, this paper focuses on the examination of the price-volume relationship around the stock price reversals (or rebounds) which enable us to truly understand the nature of price-volume relationship. In addition, we also investigate the long term price-volume relationship for the TAIEX index. 
The results strongly support our view. Our theory is helpful to explain (1) why the trading volume is always abruptly increase several (even hundred) times in the stock price rebounds (or reversals) and subsequently decrease, and (2) why there is a variety of price-volume relationship. Without a complete understanding of the interaction between information and the market demand and supply curves for equities, which is a major limitation of the analysis in this research, debates on the price-volume relationship will be ongoing. We therefore suggest that further research should extend this view of the price-volume relationship of equities (or futures). Specifically, for example, how does heterogeneous information influence the position and slope of market demand (supply) curves for equities (or futures)? How the expected return of a stock and perceived risk influences the position and slope of the market demand (supply) curve of equity (or futures)? We believe that answering such questions will help solve or clarify the price-volume relationship puzzle.

\section{References}

Ackert, L. F. \& G. Athanassakos. (2005). The relationship between short interest and stock returns in the Canadian market. Journal of Banking and Finance, 29, 729-1749. http://dx.doi.org/10.1016/j.jbankfin.2004.06.034

Admati, A. \& P. Pfleiderer. (1988). A theory of intraday patterns: Volume and price variability. Review of Financial Studies, 1, 3-40. http://dx.doi.org/10.1093/rfs/1.1.3

Assogbavi, T., Khoury, N. \& P. Yourougou. (1995). Short interest and the asymmetry of the price-volume relationship in the Canadian stock market. Journal of Banking and Finance, 19, 1341-1358. http://dx.doi.org/10.1016/0378-4266(94)00121-I

Back, K., Cao, C. H., \& G. A. Willard. (2000). Imperfect competition among informed traders. Journal of Finance, 5 , 2117-2155. http://dx.doi.org/10.1016/j.jbankfin.2004.06.03410.1111/0022-1082.00282

Bagwell, L.S. (1991). Shareholder heterogeneity: Evidence and implications. American Economic Review, 81(2), 218-221. http://dx.doi.org/10.1016/j.jbankfin.2004.06.03410.1257/aer.89.1.215

Bauwens, L., D. Rime, \& G. Sucarrat. (2006). Exchange rate volatility and the mixture of distribution hypothesis. Empirical Economics, 30(4), http://dx.doi.org/10.1016/j.jbankfin.2004.06.03410.1007/s00181-005-0005-x

Black, F. (1986). Noise. Journal of Finance, 41, 529-543. http://dx.doi.org/10.1016/j.jbankfin.2004.06.03410.2307/2328481

Blouin, J.L., J.S. Raedy, \& D.A. Shackelford. (2000). The impact of capital gains taxes on stock price reactions to S\&P $500 \quad$ inclusion, NBER Working paper, $\quad$ No. 8011. http://dx.doi.org/10.1016/j.jbankfin.2004.06.03410.2139/ssrn.247797

Bradley, M., A, Desai, \& E.H. Kim. (1988). Synergistic gains from corporate acquisitions and their division between the stockholders of target and acquiring firms. Journal Financial Economics, 21(1), 3-40. http://dx.doi.org/10.1016/j.jbankfin.2004.06.03410.1016/0304-405X(88)90030-X

Brown, D.T. \& Ryngaert, M.D. (1992). The determinants of tendering rates in interfirm and self-tender offers. Journal of Business, 65(4), 529-556. http://dx.doi.org/10.1016/j.jbankfin.2004.06.03410.1086/296584

Bui, E.A. and S.J. Jordan. (2009). Do supply curves for stocks slope up? African Journal of Business Management, 3(9), 405-409. http://dx.doi.org/10.1016/j.jbankfin.2004.06.03410.2307/2328486

Campbell, J. Y., S. J. Grossman, \& J. Wang. (1993). Trading volume and serial correlation in stock-returns. $\begin{array}{lllll}\text { Quarterly of Journal } & \text { Economics, } & 108, & 905-939 .\end{array}$ http://dx.doi.org/10.1016/j.jbankfin.2004.06.03410.2307/2118454

Chakravarty, S. (2001). Stealth-trading: Which traders' trades move stock prices. Journal of Financial Economics, 61, 307-389. http://dx.doi.org/10.1016/j.jbankfin.2004.06.03410.1016/S0304-405X(01)00063-0

Chen, G. M., Firth, M. \& O. M. Rui. (2001). The dynamic relation between stock returns, trading volume, and volatility. Financial Review, 38, http://dx.doi.org/10.1016/j.jbankfin.2004.06.03410.1111/j.1540-6288.2001.tb00024.x

Chen, K., \& W. Fong. (2000). Trading size, order imbalance, and the volatility-volume relation. Journal of Financial Economics, 57, 247-273. http://dx.doi.org/10.1016/j.jbankfin.2004.06.03410.1016/S0304-405X(00)00057-X

Chen, S. H. \& C. C. Liao. (2005). Agent-based computational modeling of the stock price-volume relation. Information Sciences, 170, 75-100. http://dx.doi.org/10.1016/j.jbankfin.2004.06.03410.1016/j.ins.2003.03.026 
Clark, P. K. (1973). A subordinated stochastic process model with finite variance for speculative prices. Econometrica, 41, 135-155. http://dx.doi.org/10.1016/j.jbankfin.2004.06.03410.2307/1913890

Copeland, T. E. (1976). A model of asset trading under the assumption of sequential information arrival. Journal of Finance, 31, 1149-1168. http://dx.doi.org/10.1016/j.jbankfin.2004.06.03410.2307/2326280

DeLong, B., Shleifer, A., L. Summers, \& R.J. Waldmann. (1990). Noise trader risk in financial markets. Journal of Political Economy, 98, 703-738. http://dx.doi.org/10.1016/j.jbankfin.2004.06.03410.1086/261703

Easley, D. \& M. O’Hara. (1987). Price, trade size, and information in securities markets. Journal of Financial Economics, 19, 69-90. http://dx.doi.org/10.1016/j.jbankfin.2004.06.03410.1016/0304-405X(87)90029-8

Epps, T. (1975). Security price changes and transaction volumes: Theory and evidence. The American Economic Review, 65(4), 586-597. http://dx.doi.org/10.1016/j.jbankfin.2004.06.03410.2307/2330293

Epps, T. \& M. Epps. (1976). The stochastic dependence of security price changes and transaction volume: Implications for the mixture-of-distributions hypothesis. Econometrica, 44, 305-321. http://dx.doi.org/10.1016/j.jbankfin.2004.06.03410.2307/1912726

Feng, L. \& M. S. Seasholes. (2004). Correlated trading and location. Journal of Finance, 6, $2117-2144$. http://dx.doi.org/10.1016/j.jbankfin.2004.06.03410.1111/j.1540-6261.2004.00694.x

Grinblatt, M. \& M. Keloharju. (1999). The investment behavior and performance of various investor types: A study of Finland's unique data set. Journal of Financial Economics, 55, 43-67. http://dx.doi.org/10.1016/j.jbankfin.2004.06.03410.1016/S0304-405X(99)00044-6

Hasbrouck, J. (2003). Intraday price formation in U.S. equity index markets. Journal of Finance, 58, $2375-2399$. http://dx.doi.org/10.1016/j.jbankfin.2004.06.03410.1046/j.1540-6261.2003.00609.x

Harris, L. (1986). Cross-security tests of the mixture of distributions hypothesis. Journal of Financial and Quantitative Analysis, 21, 39-46. http://dx.doi.org/10.1016/j.jbankfin.2004.06.03410.2307/2330989

Harris, L., \& E. Gurel. (1986). Price and volume effects associated with changes in the S\&P 500 list: New evidence for the existence of price pressure. Journal of Finance, 41, 815-829. http://dx.doi.org/10.1016/j.jbankfin.2004.06.03410.2307/2328230

Holden, C. \& A. Subrahmanyam. (1992). Long-lived private information and imperfect competition. Journal of Finance, 47, 247-270. http://dx.doi.org/10.1016/j.jbankfin.2004.06.03410.2307/2329097

Huang, R.D., \& Masulis, R.W. (2003). Trading activity and stock price volatility: Evidence from the London Stock $\begin{array}{llllll}\text { Exchange. } & \text { Journal } & \text { Empirical } & \text { Finance, } & 10, & 249-269 .\end{array}$ http://dx.doi.org/10.1016/j.jbankfin.2004.06.03410.1016/S0927-5398(02)00048-8

Jennings, R. H., L. T. Starks, \& J. C. Fellingham. (1981). An equilibrium model of asset trading with sequential information arrival. Journal of $\quad$ Finance, http://dx.doi.org/10.1016/j.jbankfin.2004.06.03410.2307/2327469

Karpoff, J.K.. (1987). The relation between price changes and trading volume: A survey. Journal of Financial and Quantitative Analysis, 22(1), 109-126. http://dx.doi.org/10.1016/j.jbankfin.2004.06.03410.2307/2330874

Kent, D., D. Hirshleifer, \& A. Subrahmanyam. (1998). Investor psychology and security market under- and $\begin{array}{lllll}\text { overreactions. } & \text { Journal } & \text { Finance, } & 53, & 1839-1885 .\end{array}$ http://dx.doi.org/10.1016/j.jbankfin.2004.06.03410.1111/0022-1082.00077

Kim, J.-W., J. Lee, \& R. Morck. (2009). Characteristics of observed limit order demand and supply schedules for

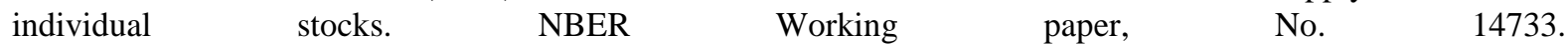
http://dx.doi.org/10.1016/j.jbankfin.2004.06.03410.2139/ssrn.521142

Kyle, A. S. (1985). Continuous auctions and insider trading. Econometrica, 53, 1315-1335. http://dx.doi.org/10.1016/j.jbankfin.2004.06.03410.2307/1913210

Lakonishok J. \& E. Maberly. (1990). The weekend effect: Trading patterns of individual and institutional investors. Journal of Finance, 45, 231-43. http://dx.doi.org/10.1016/j.jbankfin.2004.06.03410.2307/2328818

Lakonishok, J. \& Smidt, S. Maberly. (1989). Past price changes and current trading volume. Journal of Portfolio Management, 15, 18-24. http://dx.doi.org/10.1016/j.jbankfin.2004.06.03410.3905/jpm.1989.409223

Lamoureux, C. \& W. Lastraps. (1990). Heteroskedasticity in stock return data: Volume versus GARCH effect. 
Journal of Finance, 45, 221-229. http://dx.doi.org/10.1016/j.jbankfin.2004.06.03410.2307/2328817

Loughran T. \& J.R. Ritter. (1995). The new issues puzzle. Journal of Finance, 50, 23-52. http://dx.doi.org/10.1016/j.jbankfin.2004.06.03410.2307/2329238

McInish, T. H. \& R. A. Wood. (1990). A transactions data analysis of the variability of common stock returns during 1980-1984. Journal of Banking and Finance, 14, 99-112. http://dx.doi.org/10.1016/j.jbankfin.2004.06.03410.1016/0378-4266(90)90038-4

Moosa, I. A., Silvapulle, P. \& M. Silvapulle. (2003). Testing for temporal asymmetry in the price-volume relationship. Bulletin of Economic Research, 55(4), 389. http://dx.doi.org/10.1016/j.jbankfin.2004.06.03410.1111/1467-8586.00182

Odean, T. (1998). Volume, volatility, price and profit when all traders are above average. Journal of Finance, 53(6), 1887-1937. http://dx.doi.org/10.1016/j.jbankfin.2004.06.03410.1111/0022-1082.00078

Petajisto, A. (2009). Why do demand curves for stocks slope down? Journal of Financial and Quantitative Analysis, 44(5), 1013-1044. http://dx.doi.org/10.1016/j.jbankfin.2004.06.03410.1017/S0022109009990317

Rogalski, R. J. (1978). The dependence of prices and volume. Review of Economics and Statistics, 60, 268-274. http://dx.doi.org/10.1016/j.jbankfin.2004.06.03410.2307/1924980

Shleifer, A. (1986). Do demand curves for stocks slope down? Journal of Finance, 41, 579-590. http://dx.doi.org/10.1016/j.jbankfin.2004.06.03410.2307/2328486

Smirlock, M. \& L.T. Starks. (1985). A further examination of stock price changes and transactions volume. Journal of Financial Research, 8(3), 217-225. http://dx.doi.org/10.1016/j.jbankfin.2004.06.03410.1111/j.1475-6803.1985.tb00404.x

Tauchen, G. \& M. Pitts. (1983). The price variability-volume relationship on speculative markets. Econometrica, 51, 485-505. http://dx.doi.org/10.1016/j.jbankfin.2004.06.03410.2307/1912002

\section{Notes}

Note 1. Usually it lasts for several trading days, even months.

Note 2. Since March 1, 2005, IPO stocks have been exempted from the price limit rule in the TSE. Price changes for IPO stocks have no limits in the first five trading days, and then must conform to the same trading rules as ordinary stocks.

Note 3. Even all the investors know that the price of the IPO stock will increase significantly, one unit of trading volume will still occur. Since the TSE regulation stipulated that if no trading volume occur during the IPO trading period, the price changing limit in each trading day would be restricted to only half of the limit. To expedite the stock price approaching its prevailing OTC market price, some major stockholders thus would (act as a market maker and) sell a trading unit.

Note 4. Traditional economics texts point out that factors influencing the position and slope of the market demand curve for goods include consumer tastes and incomes, other commodity prices, and the number of consumers; factors influencing the position and slope of market supply curves include input prices and technological change. However, investors' decision to purchase or sell a stock is based mainly on its expected profitability and risk, which in turn represent key factors determining the position and slope of demand and supply curves. The "quality" of a stock therefore reflects its expected future profitability and risk. If the perceived quality of a stock remains unchanged, price and trading volume are inversely correlated; if it changes though, the demand and supply curves shift. This definition of "quality" helps to uncover the role of information in the price-volume relationship.

Note 5. Those who evaluate the information as much better than average will appear on the buy side; those who evaluate the information as less than average represent the sell side as the stock price increases. With obvious increase in the number of pessimists, the market supply curve will move rightward.

Note 6. If the number of pessimists is very small, the market supply curve can move far to the left, causing an increase in stock prices and decrease in trading volumes.

Note 7. If the number of pessimists is very small, the market demand curve might move only slightly leftward, causing the stock price to fall and trading volume to increase.

Note 8. The whole period covers January 1995 to December 2008. Period 1 covers January 1995 to December 1998; Period 2 covers January 1999 to December 2003; and Period 3 covers January 2004 to December 2008. 